\title{
Lusofonias editoriais: os possíveis ethé discursivos de editores independentes
}

\author{
Editorial lusophonics: the possible discourse ethos of independent publishers \\ Lusofonías editoriales: los posibles ethé discursivos de editores independientes \\ Letícia Santana Gomes $\odot$ \\ Centro Federal de Educação Tecnológica, Belo Horizonte, MG, Brasil.
}

\begin{abstract}
RESUMO
Buscamos encontrar nesta pesquisa, por meio das reflexões teóricas de Maingueneau (2008) e Amossy (2005), os possíveis ethé discursivos dos editores independentes de Língua Portuguesa. A partir do documentário Da minha língua vê-se o mar (Letícia Santana Gomes, 2017), realizado pela pesquisadora e corpus desta pesquisa, analisamos as entrevistas com os editores Alex Dau (Moçambique), Maria Mazarello (Brasil) e Vasco Santos (Portugal), em que foi possível encontrar os possíveis ethé discursivos dos editores de forma coletiva e singular. Acreditamos que o papel social revelado pelos depoentes foi a de evocação do imaginário da vinculação e da paixão da profissão com os sonhos de vida, uma predestinação ao ofício de edição. Percebemos, então, que o critério distintivo de "independente" vem também para que, como Mazza, Vasco e Alex, editores com ideias compartilhadas, de utopia e de resistência, possam buscar possíveis soluções para as suas inquietações, trazendo ethos de independência, resistência e credibilidade.
\end{abstract}

$\diamond$

Palavras-chave: Editores independentes. Ethos discursivo. Lusofonia.

\begin{abstract}
We seek to find in this research, through the theoretical reflections of Maingueneau (2008) and Amossy (2005), the possible ethé discursives of the independent editors of Portuguese Language. From the documentary "Da minha língua vê-se o mar", conducted by the researcher and corpus of this research, we analyzed the interviews with editors Alex Dau (Mozambique), Maria Mazarello (Brazil) and Vasco Santos (Portugal), in which it was possible to find the possible discursive ethos of the publishers collectively and singularly. We believe that the social role revealed by the deponents was to the evocation of the imaginary of the bondage and passion of the profession with the dreams of life, a predestination to the publishing profession. We see, then, that the distinctive criterion of "independent" is also that Mazza, Vasco and Alex, editors with shared ideas, utopia and resistance, can seek possible solutions to their concerns, bringing ethos of independence, resistance and credibility.
\end{abstract}

Keywords: Independent editors. Ethos discursive. Lusophony.

\section{RESUMEN}

Buscamos encontrar en esta investigación a través de las reflexiones teóricas de Maingueneau (2008) y Amossy (2005), los posibles ethé discursivos de los editores independientes de Lengua Portuguesa. A través del documental "Da minha língua vê-se o mar", realizado por la investigadora y corpus de esta investigación, se analizaron las entrevistas con editores Alex Dau (Mozambique), María Mazarello (Brasil) y Vasco Santos (Portugal), fue posible encontrar los posibles ethé discursivos de los editores de forma colectiva y singular. Creemos que el papel social revelado por los depoentes fue la de evocación del imaginario de la vinculación y pasión de la profesión con los sueños de vida, una predestinación al oficio de edición. En este sentido, el concepto de "independiente" viene también para que, como Mazza, Vasco y Alex, editores con ideas compartidas, de utopía y de resistencia, puedan buscar posibles soluciones para sus inquietudes, trayendo éxitos de independencia, resistencia y credibilidad.

Palabras clave: Editores independientes. Ethos discursivo. Lusofonías. 


\section{Introdução}

Iniciaremos este artigo refletindo sobre a dimensão da Língua Portuguesa, que foi o elo de escolha dos editores independentes presentes nesta pesquisa. O Português modelou a cultura e a história de diferentes povos que estabeleceram a sua identidade por meio da língua. Utilizamos o emblemático termo "lusofonia" como metáfora de uma realidade híbrida e miscigenada. Mais além, o linguista Carlos Alberto Faraco (2012, p. 32) revela-o como "[...] uma vibração especial das cordas do coração, com um senso de lírica pertença a uma indefinida comunidade transnacional e intercontinental unida pelo imaginário da mesma língua e de tudo que acompanha".

Martins (2015) chama atenção para o debate atual em que a lusofonia está inserida: a globalização e o imaginário de culturas servidas a uma única língua, o inglês. Entretanto, em relação a esse aspecto da globalização cosmopolita, a lusofonia está inserida em outro contexto, o da globalização multiculturalista, com a união de várias culturas, com promoção e respeito às diferenças. É nesse movimento multicultural dos povos que está inserido o português. Portanto:

[...] a Lusofonia, ao invés da homogeneização empobrecedora e de sentido único, estabelecida pela globalização cosmopolita, tem a virtude do heterogêneo a sedução de uma rede tecida de fios de muitas cores e texturas, uma rede capaz de resistir à redução do diverso a uma unidade artificial (MARTINS, 2015, p. 10).

Frente ao exposto, temos com os países que compõem essa comunidade lusófona o desafio de quebrar os equívocos da centralidade portuguesa, o imaginário da "colonização doce" e partir para os múltiplos imaginários lusófonos que surgiram. E mais, saber que esses imaginários lusófonos são marcados pela diferença. A "lusofonia" só poderá ser entendida como portuguesa, brasileira, angolana, moçambicana, guineense, caboverdiana, são-tomense, timorense, galega. Tendo em vista esse panorama que cerca os países lusófonos, será necessário, nas narrativas dos editores independentes do Brasil, de Moçambique e de Portugal, apontar as diferenças e as pluralidades de suas trajetórias de vida e os imaginários que os permeiam, e tendo como objetivo central desta pesquisa identificar e analisar os possíveis ethé discursivos a partir das narrativas de vida desses editores. Antes disso, iremos trazer as discussões sobre o termo independente.

\section{Independente: o esforço da definição}

É pertinente pensar a relação que se pode estabelecer do editor e de sua casa editorial, reflexão observada por
Bourdieu (2014), que afirma existir, sob a base de uma análise documental e de uma votação etnográfica, uma correspondência forte entre as características do editor e as características de sua editora - o que, a nosso ver, possibilitará essa associação a partir das narrativas dos editores. Por isso, problematizaremos o que é um editor "independente" (embora seja complexa uma possível definição), o lugar do independente no meio editorial e como o editor independente reflete o modo de ser da profissão.

Diante dos inúmeros questionamentos acerca do "independente", destaca-se o trabalho precursor do pesquisador brasileiro José Munir Jr., que defendeu a sua tese em Sociologia ${ }^{1}$ e, entre outras questões, abordou sobre quais as práticas e as representações que irão caracterizar o universo formado por editores independentes no Brasil e na Argentina. O pesquisador afirma que não há nada que possa defini-los, e que podemos tentar caracterizá-los como um adjetivo que funciona como "marcador identitário maleável", que abarca editores muito heterogêneos. É preciso deixar a definição em suspenso e escutar dos próprios editores o que para eles é ser independentes.

Como Munir Jr. aponta, a noção de editor "independente" ampliou a sua presença nos relatos de vida cultural nos últimos vinte anos. Tal presença se deve ao surgimento dos grandes grupos editoriais que seguem outra lógica de funcionamento de uma editora. Observamse, então, várias dicotomias nesse espaço editorial. De um lado, temos as pequenas, de capital familiar, do livro com qualidade literária; de outro, as grandes, com capital financeiro e o livro como mercadoria. Em meio a essa polarização, Muniz Jr. propõe classificações em torno do "independente". O título de seu trabalho, Girafas e Bonsais: editores independentes na Argentina e no Brasil (1991-2015), já expressa essas duas categorias dentro do universo independente. Assim, o pesquisador propõe a dualidade, os editores "girafa", empresários culturais que "[...] mantêm a cabeça no alto e os pés no chão" (MUNIZ JR., 2016, p. 19), caracterizados, geralmente, como editores mais velhos; e os editores "bonsai", aqueles editores que "[...] requerem muitos cuidados e estão fadados a nunca crescer" (MUNIZ JR., 2016, p. 19). Esses últimos permanecem com um catálogo pequeno e não têm pretensão de virar empresa, fazem livros nas horas vagas, como um hobby. Sendo caracterizados como editores mais jovens.

Dessa forma, ao unir os dois lados (a empresa e a simples casa editorial), ambos do universo independente,

\footnotetext{
MUNIZ JR, José de Souza. Girafas e bonsais: editores "independentes" na Argentina e no Brasil. 2016. 335 f. Tese (Doutorado em Sociologia) - Programa de Pós-Graduação em Sociologia da Faculdade de Filosofia, Letras e Ciências Humanas, Universidade de São Paulo, São Paulo, 2016.
} 
José Muniz tenta nortear os perfis editoriais escolhidos em sua pesquisa e, com isso, deixa margens para pensar, neste trabalho, mais uma categorização, para um possível nível intermediário entre girafas e bonsais. Com a escuta atenta aos editores, pensamos a partir do ethos discursivo as imagens que podemos ter dos três editores, Mazza, Vasco Santos e Alex Dau, para tentar compreender essa realidade em que estão inseridos. A seguir, entraremos para as discussões propriamente discursivas sobre o ethos.

\section{A noção de ethos discursivo}

Todo o ato de tomar a palavra implica a construção de uma imagem de si. Assim, não é necessário, segundo Amossy (2005), que o locutor faça um autorretrato. Para a sua representação, "[...] basta seu estilo, as competências linguísticas e enciclopédicas, as crenças implícitas" (AMOSSY, 2005, p.9). Essa representação de si para a autora seria o que no decorrer de seu livro Imagens de si no discurso: a construção do ethos irá conceituar o ethos.

A autora percorre as diferentes e necessárias conceituações sobre o termo. Primeiramente define o conceito como "[...] traços de caráter que o orador deve mostrar ao auditório (pouco importando sua sinceridade) para causar boa impressão: é o seu jeito". Barthes retoma as ideias de Aristóteles, que afirmava em sua obra Retórica: "É [...] ao caráter moral que o discurso deve, eu diria, quase todo seu poder de persuasão" (BARTHES, 2003 apud AMOSSY, 2005, p. 10).

Em um segundo momento, Amossy continua em seu percurso sobre o conceito de ethos e destaca que hoje os estudos da Análise do Discurso e da Pragmática definem o termo retórica de Aristóteles, como a arte de persuadir, de modo que, nesse termo, retórica seria a tentativa de compreender e de explicar como o discurso se torna eficaz. No entanto, a autora verifica que, na visão de Maingueneau, os estudos sobre ethos, com uma visão pragmática da sociedade, vieram substituir a retórica tradicional (AMOSSY, 2005).

Voltamos aqui ao conceito de ethos pensado por Aristóteles, que, a partir da retórica antiga, trouxe a tríade do ethos, pathos e logos. Essas três provas empregadas pelo orador para persuadir o seu auditório são caracterizadas por: i) ethos: o caráter do orador; ii) pathos: paixões despertadas no ouvinte; e iii) logos: o próprio discurso. Para Maingueneau, "os 'argumentos' correspondem ao logos, as 'paixões' ao pathos, as 'condutas' ao ethos" (MAINGUENEAU, 2008, p. 14, grifo do autor).

A propósito, a imagem de si é a peça fundamental da retórica, que, por sua vez, está fortemente ligada à enunciação. Para isso, é necessário recorrermos ao teórico Benveniste, já que foi o pioneiro na introdução de quadro figurativo, com a presença de um enunciador e de um locutor. $\mathrm{O}$ autor entendia a enunciação com duas figuras necessárias, sendo uma alocução, em que se estabelece uma relação discursiva com o parceiro. Ainda assim, para Amossy (2005, p. 12), é com "[...] a Pragmática aplicada que caberá desenvolver a questão da imagem de si no discurso". Passa-se da interlocução, vista com Benveniste, para a interação. Ao longo de uma troca comunicativa, os participantes exercem uns sobre os outros uma rede de influências mútuas. É nessa perspectiva que se fundamenta a função da imagem de si e do outro construída no e pelo discurso e que se manifesta nessa perspectiva interacional.

A autora destaca ainda os estudos do sociólogo Goffman. A partir das pesquisas dele, passou-se a dar enfoque à produção de uma imagem de si nas interações. Goffman mostra que em toda interação social os parceiros fornecem certa impressão de si que contribui para que ocorra uma mútua influência. Essas noções são completadas, sobretudo, pelo conceito de faces, que é "uma imagem do eu", delineado segundo certos atributos sociais, sendo partilháveis, "[...] uma vez que podemos causar uma boa imagem de nossa profissão ou de nossa fé quando acusam uma boa impressão de nós mesmos" (AMOSSY, 2005, p. 13).

Apesar da contribuição, Amossy salienta que nem Benveniste, nem Goffman utilizaram o termo ethos. O seu primeiro uso nas Ciências da Linguagem deve-se à teoria polifônica de Ducrot. No entanto, o estudioso não desenvolveu uma reflexão sobre o conceito.

Por fim, a noção contemporânea de ethos que abordamos atualmente se deve a Amossy e Maingueneau. Para os autores, essa noção desenvolve-se de forma articulada à de cena de enunciação ${ }^{2}$. $\mathrm{O}$ pesquisador também a relaciona à noção de tom, que remete tanto à escrita quanto à fala, como iremos abordar mais adiante.

Para Maingueneau, o ethos está ligado à enunciação, que irá se desdobrar no registro do mostrado e do dito. Nesse sentido, o público constrói representações do enunciador antes mesmo que ele fale. É por isso a primeira distinção que Maingueneau faz acerca do ethos discursivo e do ethos pré-discursivo. O primeiro refere-se à noção aristotélica, como já explicamos anteriormente. $\mathrm{O}$ segundo parte do princípio que o fato de um coenunciador não saber, previamente, o caráter do enunciador, não significa que ele não saiba, por exemplo, em qual gênero

\footnotetext{
A noção de ethos para Maingueneau está associada à cena de enunciação, que integra três cenas: i) cena englobante: tipo de discurso; ii) cena genérica: contrato associado a um gênero; e iii) cenografia: não é imposta pelo gênero, mas construída pelo próprio texto (MAINGUENEAU, 2004).
} 
discursivo pertença ou a um certo posicionamento ideológico. Em termos pragmáticos, "[...] o ethos se desdobra no registro do 'mostrado' e, eventualmente, no do 'dito"'. (MAINGUENEAU, 1984 apud AMOSSY, 2004, p. 70).

O termo tom também é utilizado para a conceituação do ethos. Até em um texto escrito, existirá uma vocalidade específica, que permite relacioná-lo a uma fonte enunciativa. $\mathrm{O}$ autor ressalta que a vocalidade implica uma determinação do corpo do enunciador. Assim, a leitura faz emergir uma origem enunciativa, uma instância subjetiva encarnada que exerce o papel de fiador. Essa figura o leitor quem deve construir, com base em indícios textuais, sendo investido de um caráter e de uma corporalidade. A qualidade do ethos remete à figura do fiador que, mediante a sua fala, concebe uma identidade compatível com o mundo que se supõe que ele faz surgir em seu enunciado (MAINGUENEAU, 2004).

Portanto, Maingueneau afirma que o enunciado se dá pelo tom de um fiador associado a uma dinâmica corporal, sendo que o leitor não codifica o sentido, mas participa, fisicamente, do mesmo mundo do fiador:

O co-enunciador captado pelo ethos, envolvente e invisível, de um discurso, faz mais do que decifrar seus conteúdos. Ele é implicado em sua cenografia, participa de uma esfera na qual pode reencontrar um enunciador que, pela vocalidade de sua fala, é construído como fiador do mundo representado (MAINGUENEAU, 2004, p. 90).

No entanto, Maingueneau (2008) pondera que, apesar de o ethos estar ligado fortemente ao ato de enunciação, ele existe antes mesmo que o enunciador fale. Assim, há o ethos discursivo e o ethos pré-discursivo.

- o ethos é uma noção discursiva, ele se constrói através do discurso, não é uma "imagem" do locutor exterior a sua fala;

- o ethos é fundamentalmente um processo interativo de influência sobre o outro;

- é uma noção fundamentalmente híbrida (sóciodiscursiva), um comportamento socialmente avaliado, que não pode ser apreendido fora de uma situação de comunicação precisa, integrada ela mesma numa determinada conjuntura sócio-histórica (MAINGUENEAU, 2008, p. 17, grifo do autor).

Em síntese, a tipologia do ethos para Maingueneau resulta da interação de diversos fatores. Temos o ethos pré-discursivo como a imagem que o coenunciador constrói de seu enunciador, antes que este pronuncie algo, e o ethos discursivo englobando o ethos dito e o ethos mostrado. A diferença entre eles seria instável, “[...] uma vez que é impossível definir uma fronteira nítida entre o 'dito' sugerido e o 'mostrado' pela enunciação" (MAINGUENEAU, 2008, p. 18). No entanto, inferimos que o ethos dito é criado por meio das referências diretas a um enunciador, já o ethos mostrado entraria no domínio do não explícito, que não está posto no texto, mas construído com pistas na interação discursiva. Já o ethos efetivo, construído também pelo destinatário, é o resultado de várias instâncias. Para demonstrar essas interações, segue o esquema proposto por Maingueneau (Figura 1):

Figura 1 - Ethos discursivo

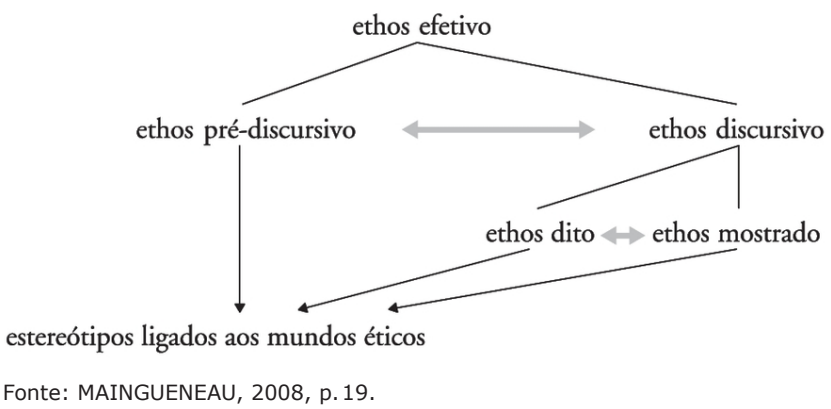

É relevante destacar que no início do esquema estão os estereótipos como forma do coenunciador mobilizar imaginários socioculturais e modelos pré-construídos para atribuir características ao enunciador. Ressaltamos o conceito mencionado por Maingueneau de estereótipos para acentuar a característica do ethos quando vinculado às representações sociais; quando assim, ele pode estar ligado a indivíduos e grupos, ou seja, a um ethos coletivo.

\section{Perfis editoriais: os editores independentes ${ }^{3}$}

O documentário Da minha língua vê-se o mar (Letícia Santana Gomes, 2017) ${ }^{4}$ é produto e corpus desta pesquisa, cuja inserção é relativamente distinta das formas tradicionais que são apresentadas na academia. Afirmamos isso porque tínhamos interesse em encontrar algum material audiovisual que pudesse ter o relato de vida de editores de livros "independentes", mas com algo que os unia: a Língua Portuguesa. Como não encontramos referências textual ou audiovisual, a intenção foi

\footnotetext{
Discussão iniciada pela pesquisadora no Intercom 2017. Disponível em: http://portalintercom.org.br/anais/nacional2017/resumos/R12-0093-1. pdf. Acesso em: 7 dez. 2017.

4 Documentário disponível em: https://vimeo.com/250715676. Acesso em: 26 jun. 2019.
} 
de "criá-las" e começar por onde ainda é um caminho insólito.

Para a realização do documentário Da minha língua vê-se o mar, o percurso inicial foi a realização de um roteiro de perguntas semiestruturadas aos editores e, depois, a gravação das entrevistas. Foram cerca de oito horas de material bruto, mas, seguindo o roteiro de edição - que foi concretizado, de fato, na ilha de edição -, foi realizada uma decupagem do material para orientar a montagem do filme, tendo que recortar e selecionar as falas que entrariam para a narrativa. No entanto, essas falas pediam ligações interdiscursivas, com imagens, sons e outros artefatos semióticos que colocaram a narrativa de uma forma mais poética. Tínhamos pensado em um filme que cada editor pudesse ter o seu relato com apenas um depoimento direto, sem interferência de outras vozes, mas o dialogismo falava mais alto. Era necessário um cruzamento de vozes e uma dinâmica das cenas que pudessem dar conta de tantos temas em comum que precisavam permitir uma alternância e dinamicidade para a narrativa fílmica.

Para o roteiro de perguntas, utilizamos uma análise da pesquisadora argentina Leonor Arfuch (2010) que nos afirma ser possível elencar as partes que compõem geralmente uma entrevista, de maneira que essa configuração está ligada à questão da identidade, não só para demonstrar quem é quem para o entrevistador, mas para se atualizar e se reconhecer. Por isso, destacamos essas etapas elencadas por Arfuch (2010) que podem ser identificadas em biografemas. Barthes (2003) propõe um conceito para biografemas, que seria uma espécie de "anamnese factícia", ou uma representação dos fragmentos de uma vida. Espécie de invenção pautada em um modelo real-imaginário que visa a completar ou garantir contornos específicos a uma biografia. Foram esses biografemas que utilizamos como critérios para a construção do roteiro do documentário e para nossas análises.

a) A infância: será a ancoragem obrigatória de todo devir. O biografema da infância será alimentado por detalhes ilustrativos e lúdicos. Além disso, o entrevistador será o privilegiado em ganhar o tom confidencial da narrativa.

b) A vocação: Arfuch (2010) afirma, com veemência, que dificilmente existiria outro gênero discursivo que imprimisse a ênfase no trabalho como o verdadeiro motor do devir humano.

c) A afetividade: seria a grande zona de competência da entrevista, a exibição pública da afetividade.

Para as análises neste artigo, utilizamos o biografema vocação, com trechos dos editores que retratam a sua visão do trabalho. Com a impossibilidade de definir com apenas um adjetivo o termo independente, como já discutimos, separamos os trechos em que é perceptível pensar o que é ser independente para cada um dos editores apresentados e entender a realidade em que estão inseridos.

Destacamos a escolha desses três editores pela trajetória alcançada e a experiência de vanguarda no cenário editorial dos países de origem. Assim, a seguir descrevemos o perfil editorial de cada um deles e a perspectiva independente atrelada às narrativas de suas vidas. A posteriori, iremos elencar os possíveis ethé comuns e individuais dos editores, nossa principal categoria de análise nesta pesquisa. A seguir, descrevemos os perfis e trechos da entrevista com os editores.

\section{Mazza Mazzarello: "grande eu não iria ser"}

A editora Maria Mazarello Rodrigues, brasileira, nascida em Ponte Nova, Minas Gerais, é negra e de origem familiar humilde. Ao se referir à sua trajetória, relata em seu depoimento um problema social: o racismo. Por ser negra, mulher e pobre, enfrentou barreiras que serão detalhadas mais adiante por meio de nossos operadores analíticos e em um capítulo específico para nossas análises. Neste tópico, iremos trazer a sua característica como editora independente.

Poucos a conhecem pelo nome completo; ela e a editora estão imbricadas até mesmo pelo apelido: Mazza. É assim que tanto a editora, quanto a sua casa editorial são conhecidas e indissociáveis. Mazza, depois de sair do interior, muda-se para Belo Horizonte, encontra um emprego de faxineira em uma gráfica e descobre-se maravilhada pela composição. É convidada, um tempo depois, a coordenar a impressão da gráfica. A partir daí, consegue adentrar o universo editorial, sendo que, mais tarde, faz o curso de Comunicação Social na Universidade Federal de Minas Gerais e consegue uma bolsa de mestrado na Universidade de Paris para estudar Editoração. Segundo a editora, foi na Europa que viu "negros de verdade" e editoras cujo objetivo era reunir autores, livros, ilustradores e personagens negros. Assim, volta ao Brasil com a utopia de fazer uma editora voltada às publicações afro-brasileiras, e justifica: "[...] eu sabia que grande eu não iria ser"; mas resolve enfrentar essas dificuldades. Ao retratar a sua casa editorial, refere-se:

Eu sabia que grande eu não iria ser, especialmente pela linha que eu resolvi trabalhar. Foi muito difícil porque, na verdade, o Brasil e até hoje, não admite que é um país racista. A dificuldade, na verdade, como pequena editora foi desde o princípio para chegar a conseguir publicar. E ilustrador? Não tinha ilustrador negro ou ilustradora que trabalhava com a questão da negritude! Esse foi um trabalho que a Mazza Edições fez, eu fiz muito. Acabou que a Mazza Edições 
chegou na frente, em termos de ser a primeira editora brasileira, realmente, a encarar a temática, a trabalhar na temática, isso, nacionalmente, o pessoal reconhece que foi a Mazza Edições que topou essa empreitada 5 .

Sobre o conceito de independente que Mazza sustenta, refere-se que é sempre uma "[...] batalha", sabia que “[...] grande eu não ia ser", mas preferiu selar o nome de sua editora em um catálogo com publicações de temáticas étnico-raciais, atendendo a um público verdadeiramente brasileiro. Observamos um deslizamento enunciativo acerca de sua editora. Em um primeiro momento, afirma, em terceira pessoa, que a Mazza Edições quem fez esse trabalho, logo em seguida já a coloca em seu discurso " $E u$ fiz muito". Percebe-se, então, o papel social de editora vinculado à sua narrativa pessoal, o que iremos abordar mais detalhadamente no terceiro capítulo.

Em relação aos apontamentos teóricos sobre o independente, percebemos que Mazza se adequaria a um perfil "intermediário", conforme a categoria tratada por Muniz Jr. (2016), com o perfil da editora que não vai crescer, embora tenha se sustentado durante muitos anos com o seu catálogo, e sendo movida por uma idealização muito forte.

\section{Vasco Santos: "o livro não é uma mercadoria"}

Vasco Santos é português, nascido em uma família de classe média, mas dentro de um contexto europeu, destoando-se da situação do Brasil e de Moçambique. Começou a cursar Medicina na Universidade de Coimbra, mas teve um forte envolvimento com a Psicologia e mudou de curso. Na mesma época, em meados dos anos 1970, influenciado pelas obras literárias e filosóficas, fundou a revista literária Fenda, que mais tarde também deu nome à sua editora. Selecionamos alguns trechos do depoimento de Vasco em que podemos caracterizar as suas percepções editoriais:

Independentes desses dois grupos e independentes dessa lógica. Podíamos dizer que é uma rede de independentes, de livrarias, tal como de editores independentes, é um editor ou um livreiro ainda romântico, que seleciona o seu catálogo, não em primeiro lugar por razões mercantis, comerciais, o livro não é apenas uma mercadoria como outra mercadoria qualquer, mas é sobretudo um instrumento de cultura e de emancipação do sujeito e de construção imaginativa do mundo pessoal e do mundo que nos rodeiam. E, portanto, as editoras independentes, eu acho que se definiria esse instrumento em dois gêneros: as editoras

\footnotetext{
5 Transcrição de trecho do depoimento de Maria Mazarello Rodrigues, no documentário Da minha língua vê-se o mar (2017), 00:43:38 a 00:45:00. Disponível em: https://vimeo.com/250715676. Acesso em: 5 jun. 2019.
}

como a Fenda, que publicam livros, eu diria, livros de inquietação, livros que criam assombro, livros também alguns politicamente radicais, fortes e as editoras independentes que publicam basicamente poesia ${ }^{6}$.

Mas ambos têm em comum a mesma paixão pelo livro, não apenas como mercadoria, mas como veículo do conhecimento. Conhecimento em termos gerais. E nesse aspecto Portugal é um oásis, ainda assim, na Europa. Talvez França ainda também tem pequenas editoras, mas por exemplo, a Inglaterra, é quase impossível hoje, publicar-se poemas, um livro de poemas, quer dizer, o mercado tá completamente canibal.

Vasco chama atenção para a vinda dos conglomerados que entendem o livro como uma mercadoria, destacando que o termo independente viria para aquelas editoras que estão na contramão desses grandes grupos. $\mathrm{O}$ editor também propõe uma suposta dicotomia entre as editoras independentes, que seriam, para ele, divididas em dois tipos, aquelas que vendem poesias, e outras, como a editora dele, que vendem outros gêneros, mas sem perder em vista o livro como veículo de conhecimento. Percebemos, então, um engajamento e uma paixão pelo universo livreiro por parte de Vasco Santos. Sendo um intelectual, dividindo o seu trabalho como editor e como psicanalista, enxerga o livro como meio de emancipação do sujeito, como potência a um ser humano, como meio de subversão e idealização. Com esse pensamento, resiste aos grandes grupos e a sua editora continua em meio aos conglomerados econômicos do mercado editorial. Como retrataria Bourdieu (2014), temos com Vasco a visão de um editor heroico e, em certa medida, que pretende um equilíbrio entre o dinheiro e a arte. Seguindo as categorias "girafa e bonsai", a visão do editor da Fenda Edições encontrar-se-ia em um nível intermediário, que visa pretensões maiores, mas não perde a essência literária e cultural que o livro pode trazer.

\section{Alex Dau: "responder às necessidades dos autores"}

O editor Alex Dau é moçambicano, nascido na cidade de Quelimane, também conhecida por Pequeno Brasil. É escritor e, devido a essa atividade, criou a sua própria editora, a Oleba Editores, que surgiu da necessidade de dar assistência aos autores. Alex não teve nenhuma formação acadêmica relacionada ao ofício de editor, principalmente por Moçambique ser carente de incentivos nessa área. $\mathrm{O}$ editor é autodidata e obteve aprendizados práticos. Paralelo ao seu trabalho como editor, é informático e cineasta por alguns momentos. Sobre o que é ser independente, relata:

\footnotetext{
6 Transcrição de trecho do depoimento de Vasco Santos, no documentário Da minha língua vê-se o mar (2017), 00:47:01 a 00:48:52. Disponível em: https://vimeo.com/250715676. Acesso em: 5 jun. 2019.
} 
Bem, não é bem assim na contramão, mas é encontrar um meio em que eu como editor independente e o autor consigam ficar satisfeitos, tanto um como outro, consigam encontrar um meio termo para todos ficarem felizes. Então, assim, em relação as editoras de Moçambique, nós temos uma série de problemas, tem a distribuição de livros, o autor, por exemplo, depois de publicar um livro, ele fica à espera de receber seus direitos de autor, não recebe ou recebe um valor que ele acha que não vai de acordo com aquilo que foi o seu trabalho. Então, há um certo desentendimento dos autores com as editoras, então essa vontade de criar uma editora independente era pra responder às necessidades dos autores. Eu como autor sentia que eu estava sendo injustiçado. Então, encontrei uma maneira, olha... eu vou fazer, vou ser um editor independente aí pelo menos eu consigo, eu sei onde estão os problemas e vou tentar sanar esses problemas. Por exemplo, a distribuição é muito fraca em Moçambique. Eu sei dizer, uma editora levar o livro, querer fazer distribuição, não chega lá. O livro pode levar até 5 anos ou 10 e o autor está à espera dos seus direitos de autor, percebe? Então isso é um grande problema. Então, o que eu faço, eu aconselho os autores, a melhor maneira de seu livro foi vendido é este, a melhor maneira de tu fazer o seu livro é assim, e uma das coisas que eu faço com uma editora independente é tiragens reduzidas, 100, 200, 300. Então, as outras editoras eles fazem uma tiragem muito grande e, depois, pra ser vendido, leva um processo muito, muito, muito longo. E eu sei que, para se vender um livro em Moçambique é complicado, o poder de compras do moçambicano também é reduzido, é, principalmente quando se trata de comprar livros. Então, existe uma plataforma para nós fazermos facilmente com que o livro chega às pessoas, que é através de lançamentos, através de convívios, de intercâmbios, a gente põe os livros à venda, a gente interage com os leitores, apresentação dos livros nas faculdades, nas escolas, então essas são as plataformas que encontramos de fazer contato com os leitores e pôr o livro ao alcance deles ${ }^{7}$.

Alex Dau revela o independente como meio termo tanto para o editor quanto para o autor, para que ambos possam se beneficiar. Por ter experiência como autor, resolveu criar a sua própria editora, de maneira que atendesse a outras lógicas de apoio ao escritor. É importante inferirmos que o conceito de independente em Alex Dau também está vinculado ao sentido de independência da própria nação, que teve a sua emancipação tardia, apenas em 1975 e, consequentemente, uma insuficiência do País em diversas esferas públicas, sobretudo, a cultural. O editor e autor ressalta os problemas com a distribuição, também comum no Brasil, a dificuldade com os direitos

\footnotetext{
Transcrição de trecho do depoimento de Alex Dau, no documentário $D a$ minha língua vê-se o mar (2017), 00:39:58 a 00:43:37. Disponível em: https://vimeo.com/250715676. Acesso em: 5 jun. 2019.
}

autorais e o poder de compra do povo moçambicano, que é reduzido. Com Alex, percebemos uma visão de que ser independente facilitaria o acesso aos livros para o público leitor, de colocar os livros "ao alcance deles". Poderíamos categorizá-lo, conforme José Muniz, como o editor "bonsai", em que as pretensões são de deixar o catálogo pequeno, mas com obras significativas e que possam chegar aos leitores. Inserido em Moçambique e diante de dificuldades que já foram superadas por Portugal e, sobretudo, pelo Brasil, ser independente em Moçambique é resistir e ser "heroico".

\section{Ethos discursivo nas narrativas de vida dos editores independentes}

Observamos o ethos coletivo, global, comum aos três editores entrevistados, são eles: de ascendência, de testemunha, de competência, de resistência, de independência e de utopia.

\section{Ethos de ascendência}

Como reflete Caeiro (2016), há uma projeção etótica de forma ascendente, de baixo para cima, com a ideia de crescimento no sentido positivo. Dessa forma, foi possível observar, sobretudo em Mazza, um discurso permeado de efeitos patêmicos, o qual pressupõe uma trajetória de vida ascendente, começando como faxineira de uma gráfica até se tornar editora. Assim como Vasco e Alex, que projetam positivamente as trajetórias das vidas deles.

\section{Ethos de testemunha}

Charaudeau (2006) nos apresenta que não está ligado à identidade social do sujeito, mas resulta de uma construção discursiva pelo sujeito falante, de tal modo que os outros podem julgar aquele acontecimento narrado por meio de uma experiência vivida. O sujeito demonstra o seu conhecimento de maneira clara, evocando memórias e vozes, em uma condição de sinceridade. É perceptível, portanto, em Mazza, Vasco e Alex que, por meio de fragmentos das vidas deles, mobilizem alguns acontecimentos que para eles são relevantes e se tornem testemunhas de momentos também históricos.

\section{Ethos de competência}

Exige saber e habilidade, um domínio particular na atividade que exercem. Características que invocam esse percurso: herança, estudos, funções exercidas, experiência adquirida. Mazza, Alex e Vasco assumem a competência por terem um papel decisivo na cadeia editorial e um compromisso profissional de se aperfeiçoar e buscar a 
melhoria das produções, atrelado a uma característica "independente".

\section{Ethos de independência}

Como apontado no decorrer deste artigo, a ideia emblemática do "independente" está associada a diferentes características para cada editor. Em Mazza, percebemos a imagem de independente atrelado a um perfil militante. Embora tenha sido uma batalha conseguir abrir uma editora independente, persiste em continuar com publicações voltadas à temática afro-brasileira, motivada pela sua trajetória de vida. Em Vasco, o ethos independente está associado à mudança de curso, sem que a postura contrária do pai pudesse convencê-lo da decisão. Vasco aposta nas publicações dos livros de assombro, de literatura, capazes de subverter a lógica do pensamento, é a independência também do sujeito leitor e dos próprios grupos oligopólios que canibalizam o mercado. Por fim, em Alex ressaltamos o ethos independente ligado à questão de libertação nacional, de uma busca para concretização de uma literatura moçambicana, atrelado ao papel do editor como alguém que deve ajudar o autor.

\section{Ethos de resistência}

O ethos que emerge das práticas discursivas dos três editores está atrelado à resistência, marcada por uma busca dos editores de que as suas produções sejam respaldadas por valores literários e artísticos das obras, pela busca de um público leitor e de sua formação crítica, resistindo à vinda dos oligopólios (Vasco), do preconceito existente na sociedade (Mazza) e a busca de uma literatura nacional (Alex). As posturas dos editores geram alguns efeitos de sentido, como a força e a coragem, já que, apesar de terem enfrentado diversos percalços em suas vidas, resistem e persistem, utilizando-se dessas características como resposta para seguir a caminhada.

\section{Ethos de utopia}

Por meio das narrativas de vida dos editores, percebemos que as escolhas profissionais foram guiadas por algo que os próprios editores colocaram como algo utópico. A escolha para a profissão de editor, ora ao acaso, como em Mazza, ora por um interesse, como em Alex e Vasco, são marcadas pela utopia, em uma tentativa de mudar o cenário editorial. Para Mazza, a utopia existe para dar continuidade à batalha dela; para Vasco, a visão quase utópica estabelece-se por sonhar que poderá sobreviver fora de um sistema econômico capitalista; já em Alex, a busca de uma libertação, de fato, de Moçambique.

No Quadro 1, demonstramos os possíveis ethé discursivos dos editores independentes que foram apontados no decorrer das análises.

Quadro 1 - Os ethé discursivos em Maria Maria Mazarello, Vasco Santos e Alex Dau

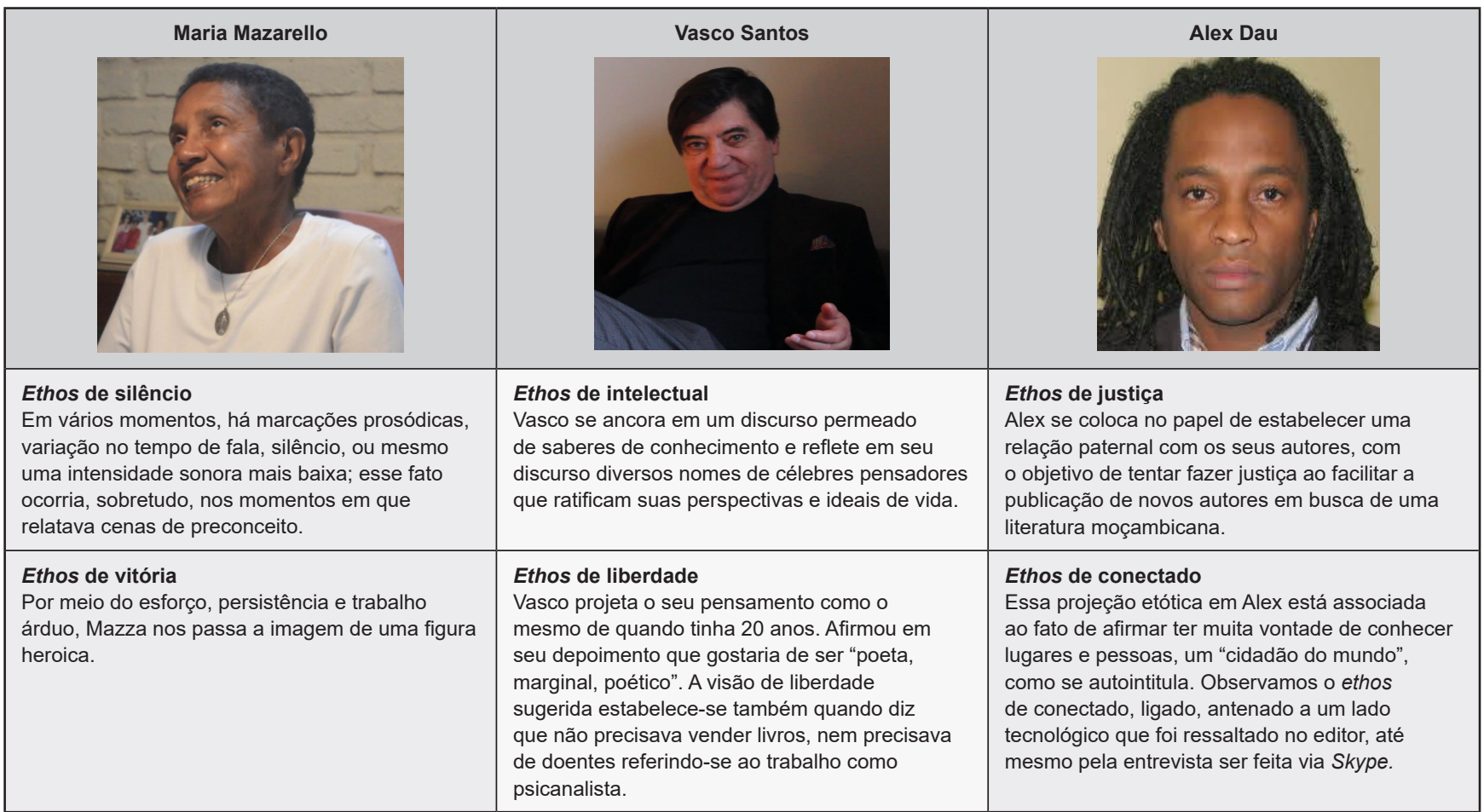




\section{Considerações finais}

Assim, percebemos que o ethos individual e coletivo dos editores está atrelado ao de profissionais que vivem "de" livro e/ou para os livros, sendo responsáveis pela difusão e pela memória cultural, literária, artística e ideológica. Cabe-lhes o complexo exercício de avaliar e selecionar em meio ao universo cultural. São profissionais que amam a sua profissão, confundindo-a com a própria história pessoal.

Com esse quadro, estabelecemos os possíveis ethé discursivos dos editores de forma individual. Acreditamos que o papel social revelado pelos depoentes foi de evocação do imaginário da vinculação e paixão da profissão com os sonhos de vida, uma predestinação ao ofício de edição.

\section{Referências}

AMOSSY, Ruth (org.). Imagem de si no discurso: a construção do ethos. São Paulo: Contexto, 2005.

ARFUCH, Leonor. O espaço biográfico: dilemas da subjetividade contemporânea. Trad. Paloma Vedal. Rio de Janeiro: EDUERJ, 2010. https://doi.org/10.22409/ geographia2009.v11i22.a13587

BARTHES, Roland. Roland Barthes por Roland Barthes. São Paulo: Estação Liberdade, 2003. https://doi. org/10.1515/9783110279818-153

BOURDIEU, Pierre. Una revolución conservadora en la edición. In: INTELECTUALES, politica y poder. Eudeba: Buenos Aires, 2014.

CAEIRO, Leila Marli de Lima. Parceiros do MG TV: Voz da comunidade no telejornalismo mineiro - de quem é o discurso? 2016. 176f. Dissertação (Mestrado em Estudos de Linguagens) - Programa de Pós-Graduação em Estudos de Linguagens, Centro Federal de Educação Tecnológica de Minas Gerais, Belo Horizonte, 2016. https://doi.org/10.5752/ p.2175-5841.2018v16n51p1433

CHARAUDEAU, Patrick. Discurso político. São Paulo: Contexto, 2006.

DA MINHA língua vê-se o mar. Direção: Letícia Santana Gomes. Belo Horizonte, 2017. (102 min). Disponível em: https://vimeo.com/250715676. Acesso em: 5 jun. 2019.

MAINGUENEAU, Dominique. A propósito do ethos. In: MOTTA, Ana Raquel; SALGADO, Luciana (org.). Ethos discursivo. São Paulo: Contexto, 2008. p. 11-25.

MAINGUENEAU, Dominique. Novas tendências em análise do discurso. Campinas (SP): Pontes, 1997.

MAINGUENEAU, Dominique. Análise de textos de comunicação. São Paulo: Cortez; 2004. https://doi. org/10.18309/anp.v1i12.518
MAINGUENEAU, Dominique. A propósito do ethos. In: MOTTA, Ana Raquel; SALGADO, Luciana (org.). Ethos discursivo. São Paulo: Contexto, 2008. p.11-25.

MARTINS, Moisés de Lemos. Apresentação: lusofonias reinvenção de comunidades e combate linguístico-cultural. Disponível em: https://goo.gl/TV19su. Acesso em: $10 \mathrm{dez}$. 2015.

MUNIZ JR., José de Souza. Girafas e bonsais: editores "independentes" na Argentina e no Brasil. 2016, 335f. Tese (Doutorado em Sociologia) - Programa de Pós-Graduação em Sociologia da Faculdade de Filosofia, Letras e Ciências Humanas, Universidade de São Paulo, São Paulo, 2016. https://doi.org/10.29381/0103-8559/2019290134-42

Recebido em:5/10/2018.

Aprovado em: 27/6/2019.

Publicado em: 30/11/2019.

Autora:

Letícia Santana Gomes

Mestre e doutoranda, Centro Federal de Educação Tecnológica, Belo Horizonte, MG, Brasil.

Orcid: https://orcid.org/0000-0002-3210-9508

E-mail: leticiasantanag@gmail.com

Endereço: Av. Amazonas, 5253 - Nova Suíça

30421-169, Belo Horizonte, MG, Brasil 